\title{
Economic Impact of Research Results on Local Social and Economic Development
}

\author{
Vo Hai Quang', Nguyen Dinh Binh ${ }^{2}$, Nguyen Huu Xuyen ${ }^{3}$ \\ ${ }^{1}$ Nghe An Department of Science and Technology, Vietnam \\ ${ }^{2}$ National Technology Innovation Fund, Vietnam \\ ${ }^{3}$ National Institute of Patent and Technology Exploitation, Vietnam
}

Corresponding Author: Nguyen Huu Xuyen

\begin{abstract}
Science and technology (S\&T) is the driving force of economic growth, this has been recognized by many countries around the world. In Vietnam, the results of S\&T research at the local level (provincial level) have important implications for social, economic development. Promote application of S\&T research results interested by the Party and the State, which are confirmed in many resolutions and legal documents of Vietnam. By the research method combining quantitative and qualitative, with the use of primary and secondary data, the paper clarifies the economic impact of $S \& T$ research results from S\&T tasks (case study in Nghe An province of Vietnam), were accomplished from 2005 to 2015 and their impact from 2016 to 2020 on social, economic development of Nghe An province. From there, recommending solutions and policies to promote social, economic development of Nghe An province based on S\&T development.
\end{abstract}

Keywords: Economic impact, Nghe An S\&T

\section{RESEARCH OVERVIEW}

The impact assessment of S\&T has important implications for the completion of S\&T policies, thereby promoting economic, social development based on S\&T foundation. However, the assessment of the impact of S\&T research results on the social, economic development of countries, localities or fields is important not only to science, but also to the state, governments at all levels, and enterprises. Up to now, the world has formed a number of theories and methods to assess the impact of S\&T research results on the social, economic, the assessment methods are still diverse, inconsistent. According to Deketele (1999), the assessment can be understood as a comparison of the suitability between a set of valuable and reliable information with a set target. The assessment is the process of gathering, analyzing evidence to reach conclusions about a problem. In S\&T activities, assessment is a professional activity, conducted in a systematic manner with a clear purpose based on the appropriate order, procedures, principles and standards to make judgments, conclusion is based on real evidence (Laws, 2006). According to Gertler and Paul J et al (2016), impact assessment is a series of specific assessments that seek to answer the question of cause and effect: The impact of a program, topic or project on What are the desired results? What will happen to beneficiaries of the program, topic or project if there is no program, topic or project?

Regarding the post-accomplished assessment method, according to Fasella (1996), the assessment of S\&T tasks is often used through the Council to evaluate by expert method. Although it is possible to provide a clear indicator system, when evaluating and using them depends on many factors with different criteria (Clarke, Thomas E, 1996). Therefore, the introduction of an indicator system applicable to all assessments is still a matter 
of debate. Indicators for research with specific goals are mainly based on the cost/benefit ratio. Common methods and tools used in impact assessment are presented by the World Bank in the impact assessment manual (Dina Pomeranz Deborah, 2011), include: Pre-post method ; randominzed evaluation; propensity score matching; diffenences in differences; regression discontinuity; simple difference.

In Vietnam, the clarification of the concept of impact assessment of S\&T research result has attracted organizations and individuals such as Nguyen Khac Minh and Giang Thanh Long (2007), National Institute for Science and Technology Policy and Strategy Studies (NISTPASS, 20072008), Vietnam Centre for Science and Technology Valuation (VISTEC, 2020),.... S\&T research result from S\&T tasks are integrated into S\&T programs, each of which builds up on targets. In fact, the concept of impact assessment is also widely used in topics and projects related to environmental issues, assessing the impact of the 4th industrial revolution on the industrial structure. The scientific, transparent and fair assessment and acceptance will contribute to creating a supply of quality technology with commercialization potential (Nguyen Huu Xuyen et al., 2018, 2020). Besides, S\&T research result has a positive impact on economic development ( $\mathrm{Vu}$ Cao Dam, 2006; Tang Van Khien, 2008) and depending on the evaluation method. Evaluation, acceptance of the results of the performance of S\&T tasks is an important step in the management of S\&T tasks.

According to the Vietnam Law on Science and Technology (2013), S\&T tasks are $S \& T$ issues that need to be resolved to meet the practical requirements of social, economic development, ensuring national defense, security, and S\&T development. The assessment of the impact of researches on topics, projects through provincial S\&T tasks has many implications for the local socio-economic development (Vo Hai Quang et al., 2019). Impact assessment criteria often refer to long-term effects or changes brought about by the program, usually economic, social and environmental changes. This paper focuses on assessing the economic impact of research results on national, regional and local social, economic development. The criteria reflecting the economic impact of research results through the provincial S\&T tasks using the state budget on the local social, economic development include:

- Impact on perception of the role of S\&T in economic development;

- Impacts on the economic structure of the locality;

- Impact on enterprises' investment in local production technologies;

- Impact on local budget spending on product completion and development generated from S\&T tasks;

- Impact on research activities to create products/services for local economic development;

- Impact on the formation of S\&T enterprises from post-acceptance research results

\section{RESEARCH METHOD}

In order to achieve the goal, the authors have inherited and developed researches published related (hard copy, soft version) to $S \& T$, the impact of $S \& T$, policy promote the application of $S \& T$ results and the economic impact of S\&T to social, economic development; at the same time, researching some typical policies to promote the application of S\&T advances in practice in Nghe An province in the period 2005 to 2020.

The authors conducted 12 in-depth interviews and 1 group discussion with representatives of cooperatives, individual business households and enterprises in Nghe An province, representing Vinh City, Cua Lo Town, Thai Hoa Town and the districts of Nam Dan, Do Luong, Con Cuong, Ky Son, Nghi Loc, Dien Chau, Quynh Luu, Quy Hop and Que Phong. In 12 interviews, there were 4 face-to-face interviews and 8 telephone interviews, because Nghe An is a 
large province with complicated topography. Next, the authors sent questionnaire to 420 cooperatives, individual business households and business in Nghe An province (21 districts, towns and cities). Collected 396 forms of complete information (reaching 94.3\%). The number of questionnaire did not have enough information was 24 (5.7\%). In addition, after screening, the invalid questionnaire were removed as those that did not fill in all the answers, did not fill in general information, some answer sheets but were inconsistent, so having 381 valid answer sheets were used for official analysis.

\section{RESEARCH RESULTS}

\subsection{S\&T tasks of Nghe An in the period 2005-2015}

In the period 2005-2015, S\&T activities in Nghe An were organized under 12 key programs with a total of 345 tasks of provincial level (including topics and projects) (Table 1).

\begin{tabular}{|l|l|l|l|l|l|l|}
\multicolumn{7}{|c|}{ Table 1: Provincial S\&T tasks in Nghe An, 2005-2015 } \\
\hline Field & Agriculture and fisheries & $\begin{array}{l}\text { Health } \\
\text { care }\end{array}$ & $\begin{array}{l}\text { Information } \\
\text { Technology }\end{array}$ & $\begin{array}{l}\text { Social science and } \\
\text { humanities }\end{array}$ & Other & Total \\
\hline $\begin{array}{l}\text { Funding } \\
\text { (million VND) }\end{array}$ & 71592.892 & 10308.746 & 9406.709 & 37325.753 & 19327.053 & 147961.153 \\
\hline Number of tasks & 168 & 32 & 31 & 66 & 48 & 345 \\
\hline $\begin{array}{l}\text { Average } \\
\text { (million VND) }\end{array}$ & 426.148 & 322.148 & 303.442 & 565.541 & 402.646 & 428.872 \\
\hline
\end{tabular}

- There are 345 tasks in 10 years, on average 34.5 tasks per year (average cost per task is 428.872 million VND). In human condition, the budget is limited in having many tasks leading to the situation that the scale of topics and projects are small, and investment in S\&T tasks is still scattered.

- In the field of research: Mainly agriculture and fisheries (168 tasks, accounting for 49\%); Social science and humanities (66 tasks, accounting for $20 \%$ ); Health care (32 tasks, accounting for $9.3 \%$ ); Information technology (31 tasks, accounting for 9.2\%); Other fields (48 tasks, accounting for 14\%). Thus, some areas are identified as key, but very few, or even have no S\&T tasks, such as industry, construction, transportation.

- Regarding the organization in charge of implementing S\&T tasks: Most of the tasks are performed by non-S\&T organizations (199/345, accounting for $57.68 \%$ ).

- Most of the tasks accepted were evaluated as excellent or fair $(35,07 \%$ excellent; $58.55 \%$ fair); only $6.09 \%$ average and 1 failed mission $(0,29 \%)$.

These are important information affecting the application efficiency and economic impact of research results from S\&T tasks using state budget to social, economic development of Nghe An province.

\subsection{Economic impacts of $S \& T$ results in the period 2005-2010 on social, economic development of Nghe An province}

According to survey of 381 cooperatives, households and enterprises in Nghe An province, it showed that the accepted S\&T results in the period 2052015 had a positive economic impact on social and economic development (Table 2):

Table 2: Economic impacts of S\&T tasks accepted in the period 2005-2015

\begin{tabular}{|c|c|c|}
\hline Criteria & Mean & Std.Deviation \\
\hline Impact on perception of the role of S\&T in economic development & 3.94 & 0.725 \\
\hline Impacts on the economic structure of the locality & 3.90 & 0.785 \\
\hline Impact on enterprises' investment in local production technologies & 3.86 & 0.758 \\
\hline Impact on local budget spending on product completion and development generated from S\&T tasks & 3.94 & 0.760 \\
\hline Impact on research activities to create products / services for local economic development & 3.84 & 0.770 \\
\hline Impact on the formation of S\&T enterprises from post-acceptance research results & 3.88 & 0.769 \\
\hline Mean & 3.89 & 0.76 \\
\hline
\end{tabular}

Source: Data processing from survey results 
Firstly, the impact on perception of the role of S\&T in economic development: $0.5 \%$ rated the impact as moderate, $48,8 \%$ rated it as positive and $22.8 \%$ rated it as very positive (mean is 3.94, standard deviation is 0.725 ).

Secondly, the impacts on the economic structure of the locality: $66.2 \%$ rated positive and very positive impact, and $33.6 \%$ said that having a normal impact (mean is 3.9, standard deviation is 0.785 ).

Thirdly, the impact on enterprises' investment in local production technologies: $63.3 \%$ rated the impact is very positive and positive and $36.7 \%$ said that normal impact (mean is 3.86, standard deviation is 0.758).

Fourth, the impact on local budget spending on product completion and development generated from S\&T tasks: $68 \%$ rated positive and very positive impact, $32 \%$ said that normal impact (mean is 3.94, standard deviation is 0.76 ).

Fifth, the impact on research activities to create products/services for local economic development: $61.1 \%$ rated positive and very positive impacts, $38.8 \%$ the respondents were normal (mean is 3.84 , standard deviation is 0.77 ).

Sixth, the impact on the formation of S\&T enterprises from post-acceptance research results: $65.1 \%$ rated positive and very positive effects, $34.4 \%$ responded with normal effects, $0.5 \%$ of respondents have a negative impact (mean is 3.88 , standard deviation is 0.769 ).

According to the survey results of 381 cooperatives, households and businesses, showed that the accepted S\&T tasks in the 2005-2015 period contributed to promoting social, economic development of
Nghe An province in $2016-2020$, specifically:

- Enhancing the role of S\&T tasks in the social, economic development of Nghe An: $73.5 \%$ of respondents strongly agree and agree, $26.5 \%$ answer normally (mean is 3,99, standard deviation is 0.725).

- Attracting non-state investment resources for S\&T tasks: $76.9 \%$ of respondents strongly agree and agree, $23.1 \%$ answer normally (mean is 4.04 , standard deviation is 0.710 ).

- Improving the management policy on S\&T tasks at provincial level: $74.2 \%$ of respondents strongly agree and agree, $25.7 \%$ answer normally (mean is 3.97 , standard deviation is 0.697 ).

- Bring the spillover to the social, economic development of local and national: $62 \%$ of respondents strongly agree and agree, $37 \%$ respond normally, $1 \%$ disagree with the content (mean is 3.76 , standard deviation is 0.708 ).

From the results of exploratory factor analysis (EFA), the model has identified four independent variables including "Availability - MucDoSanSang"; "Deploying scientific tasks- Trienkhai NVKH"; "The level of competitionMucDocanhtranh"; "The host agencyCoQuanChuTri" has the same dependent variable "Economy- KinhTe". Through factor analysis EFA, the study performed residual calculation to serve the regression analysis. Regression method helps to determine relationships between the independent variables and the dependent variable. Results of running regression analysis of economic variables are as follows (Table 3):

Table 3: Results of regression of economic impact
\begin{tabular}{|l|l|l|l|l|l|}
\hline Model Summary & \\
\hline Model & R & R Square & Adjusted R Square & Std.Deviation & Durbin-Watson \\
\hline 1 & $0.593^{\text {a }}$ & 0.352 & 0.345 & 0.499 & 1.017 \\
\hline a. Predictors: (Constant), MucDoSanSang, TrienkhaiNVKH, MucDocanhtranh, CoQuanChuTri \\
\hline b. Dependent variable: KinhTe \\
Source: Data processing from survey results \\
\hline
\end{tabular}

The results showed that the independent variable (the explanatory correlation coefficient between the variable) and the dependent variable (the 
explained variable) $\mathrm{R}=0.593$ is acceptable, thus, the regression analysis determines that between the independent variable and the dependent variable is closely correlated. In addition, the coefficient of determination $\mathrm{R}^{2}$ $=0.352$ is within the expectation, and the adjusted R 2 is 0.345 , proving the suitability of the model with collected data, although not high. This means that $34.5 \%$ of the change in the dependent variable is explained by the independent variable. Low standard deviation (0.499) indicates a low level of data dispersion, designing an efficient scale due to inheritance from previous studies. The Durbin-Watson coefficient used for multicollinearity testing is similar to the VIF (or tolerance) calculation method below and through the Durbin-Watson table look up (Table 4), the multicollinearity phenomenon did not occur in the regression analysis. Multicollinearity testing plays an important role because it can cause confusion in statistical conclusions.

Table 4: Testing regression and regression coefficients

\begin{tabular}{|c|c|c|c|c|c|c|c|c|}
\hline \multirow{2}{*}{\multicolumn{2}{|c|}{ Model }} & \multicolumn{2}{|c|}{ Unstandardized Coefficients } & \multirow{2}{*}{$\begin{array}{l}\text { Standardized Coefficients } \\
\text { Beta }\end{array}$} & \multirow[t]{2}{*}{$\mathbf{T}$} & \multirow[t]{2}{*}{ Sig. } & \multicolumn{2}{|c|}{ Confidence Interval for $\mathbf{B}$} \\
\hline & & $\mathrm{B}$ & Std.Error & & & & Tolerance & VIF \\
\hline \multirow[t]{5}{*}{1} & (Constant) & 0.269 & 0.268 & & 1.007 & 0.315 & & \\
\hline & TrienkhaiNVKH & 0.273 & 0.053 & 0.257 & 5.174 & 0.000 & 0.701 & 1.427 \\
\hline & CoQuanChuTri & 0.218 & 0.049 & 0.211 & 4.489 & 0.000 & 0.783 & 1.278 \\
\hline & MucDocanhtranh & 0.230 & 0.046 & 0.229 & 4.944 & 0.000 & 0.800 & 1.250 \\
\hline & MucDoSanSang & 0.208 & 0.047 & 0.188 & 4.412 & 0.000 & 0.946 & 1.057 \\
\hline
\end{tabular}

Source: Data processing from survey results

The results table of the regression coefficient shows the significance of the independent variables tested on the effect of the beta1 free coefficient of the research model with $95 \%$ confidence, sig. $=0.315>$ 0.05 should accept hypothesis, the coefficient betal does not affect the dependent variable (or the effect is very small and insignificant). In the standardized model of beta coefficients, the model does not include beta value or coefficient of freedom, so the removal of the coefficient of beta1 does not have a significant effect on the regression results and research objectives. The VIF coefficients are $<2$ and the Tolerance indexes are $>0.5$, proving that there is no multicollinearity phenomenon in the design model. The regression model after standardizing beta coefficients:

KinhTe $=0.257 *$ TrienkhaiNVKH $+0.211 *$ CoQuanChuTri + 0.229*MucDocanhtranh $+0.188 *$ MucDoSanSang

Inside:

- Kinhte: Economic impact

- TrienkhaiNVKH: Deploying scientific tasks

- CoQuanChuTri: The host agency
- MucDocanhtranh: The level of competition

- MucDoSanSang: Availability

\section{CONCLUSIONS AND RECOMMENDATIONS}

Research results show that "TrienkhaiNVKH" has the largest impact on the dependent variable "Kinhte", with beta = 0.257. This showed the importance of scientific research to the economic development of Nghe An province, as well as the direct impact from scientific research to the economy of the province through the formation of enterprises, and to enterprise investment for new technologies. Therefore, it is necessary to adjust the scientific research plan of Nghe An province in the coming time, strengthen the relationship between the implementation of scientific tasks and economic development to promote innovation, coordination between state management agencies and enterprises, as well as addressing limitations in the implementation, evaluation and commissioning processes of research tasks.

The second most influential level is "MucDocanhtranh", with beta coefficient = 0.229 . This shows that there is a demand in 
the market for products that are the result of scientific research, accepted by the market, and have created competition on the market. "MucDocanhtranh" from the scientific research results of Nghe An province in recent years also has an impact on "Kinhte" through the guaranteed quality of the product, which has great significance in maintaining and developing Nghe An researches to create a competitive advantage brought about by new technologies.

The independent variable "CoQuanChuTri" also has a great influence on the dependent variable "Kinhte", with the beta coefficient $=0.211$. This shows that the role of the leading agency in economic development through promoting S\&T is necessary and recognized and appreciated by organizations and enterprises of Nghe An province. These are the economic impacts through the task definition plan, research products with high application potential and high market demand. The engagement of the host agency with businesses and researchers has been really effective and recognized by the market. This shows that the lead agency has a correct development plan and needs to continue promoting its role in the coming time.

The independent variable "MucDoSanSang" has an impact on "Kinhte", with beta $=0.188$. Although the impact is not as large as the three independent variables above, this shows that ensuring scientific research also has a direct or indirect impact on the economic development of Nghe An in recent years. That is the support for new facilities, equipment, tools, space, materials, and technology to help researchers ensure the quality and time of research. The recognition of individuals, organizations and enterprises in Nghe An province on the level of willingness to serve scientific research shows that, the capacity to ensure and receive technology is quite modern, meeting the requirements of development scientific tasks with high qualifications. However, the impact on the economy is not high, so Nghe An province needs to supplement the budget and build infrastructure to promote the process of scientific research.

Thus, in order to enhance the economic impact of the S\&T tasks of Nghe An province after acceptance on economic development, it is necessary to pay attention to equal investment in aspects such as enhancing propaganda to raise awareness for all people, businesses and cooperatives about the role of S\&T in social, economic development. Based on the impact of the local economic structure, state management agencies need to pay attention to the selection of implementation tasks to promote local advantages. Encourage reciprocal enterprises when implementing S\&T tasks to maintain and replicate results when the mission ends; at the same time continue to develop and replicate the model, to assist in solving from the research stage to the dissemination to form a chain of high value products.

\section{Acknowledgement: None}

\section{Conflict of Interest: None}

\section{Source of Funding: None}

\section{REFERENCES}

1. Clarke, Thomas E (1996, "Review of Literature on Rewards and Recognition for R\&D Personnel," Nanaimo, B.C.: Stargate Consultants Limited.

2. Deketele (1999), (1999), UNESCO in action under UNSIA, Retrieved on August 2006 from

unesdoc.unesco.org/images/0015/001519/15 1917mo.pdf.

3. Dina Pomeranz Deborah (2011). Impact Evaluation Methods, World Bank.

4. Fasella (1996), International cooperation on large scientific projects: the European Experience. Final European Conference on the Yeast Genome Sequencing Network, pp. 79-90.

5. Gertler and Paul $J$ at al (2016), Impact Evaluation in Practice, Second edition World Bank. 
6. Laws (2006), Curriculum development and curriculum evaluation, Workshop material organized at Can Tho University.

7. Nguyen Huu Xuyen et al (2018), improving the quality of technology supplies through assessment and acceptance of the results of implementing S\&T tasks, Proceedings of National Conferences, NEU Publisher, Vietnam.

8. Nguyen Huu Xuyen and et al (2020), Solutions to Promote Commercialization of Research Results in Vietnamese Universities, Journal of Business and Economic Development, Issue 2, June 2020, SciencePG, doi: 10.11648/j.jbed.20200502.14.

9. Nghe An Department of Science and Technology(2019), Report on the results of implementation of Resolution 06/NQ-TW for the period 2017-2019 of Nghe An, Vietnam.

10. National Institute for Science and Technology Policy and Strategy Studies (NISTPASS, 2007-2008), Proceedings of S\&T policy research results, Youth Publishing House, Vietnam.

11. Nguyen Khac Minh, Giang Thanh Long (2007), Technical Efficiency and Productivity Growth in Vietnam: Parametric and Non-parametric Approaches, Labor publishing house, Vietnam.

12. National Assembly (2013), Law on Science and Technology, Hanoi, Vietnam.

13. Tang Van Khien (2008), "Regression analysis of the correlation of the impact of science and technology on economic development", Journal of Statistical Science Information, No. 3/2008, Vietnam.

14. Vu Cao Dam (2006), Scientific Research Methodology, Science and Technology Publishing House, Hanoi, Vietnam.

15. Vietnam Centre for Science and Technology Valuation (VISTEC, 2020), Impact assessment of Science and Technology Program: Experiences of some countries in the world and lessons for Vietnam, Hanoi, Vietnam.

16. Vo Hai Quang et al. (2019), Evaluating the effectiveness of the results of provincial S\&T tasks in the 2005-2015 period, Nghe An, Vietnam.

How to cite this article: Vo Hai Quang, Nguyen Dinh Binh, Nguyen Huu Xuyen. Economic impact of research results on local social and economic development. International Journal of Research and Review. 2021; 8(5): 330-336. DOI: https://doi.org/10.52403/ijrr.20210542 